Handbuch der Bibelhermeneutiken 



\section{Handbuch der Bibelhermeneutiken}

Von Origenes bis zur Gegenwart

Herausgegeben von

Oda Wischmeyer

In Verbindung mit

Eve-Marie Becker, Mark W. Elliott, Hans-Peter Großhans, Leonhard Hell, Karla Pollmann, Thomas Prügl, Marianne Schröter, Anselm Schubert

Unter redaktioneller Mitarbeit von Michaela Durst 
ISBN 978-3-11-032999-5

e-ISBN (PDF) 978-3-11-033027-4

e-ISBN (EPUB) 978-3-11-038992-0

\section{Library of Congress Cataloging-in-Publication Data}

A CIP catalog record for this book has been applied for at the Library of Congress.

\section{Bibliografische Information der Deutschen Nationalbibliothek}

Die Deutsche Nationalbibliothek verzeichnet diese Publikation in der Deutschen Nationalbibliografie; detaillierte bibliografische Daten sind im Internet über http://dnb.dnb.de abrufbar.

(C) 2016 Walter de Gruyter GmbH, Berlin/Boston

Titelbild: Titelblatt der „Biblia cu(m) pleno apparatu ...“ mit Martin Luthers handschriftlichen Notizen, (C bpk Satz: Konrad Triltsch, Print und digitale Medien GmbH, Ochsenfurt Druck und Bindung: Hubert \& Co. GmbH \& Co. KG, Göttingen

@ Gedruckt auf säurefreiem Papier

Printed in Germany

www.degruyter.com 